\title{
Tumor Regression Grade 5
}

National Cancer Institute

\section{Source}

National Cancer Institute. Tumor Regression Grade 5. NCI Thesaurus. Code C140894.

Presence of tumor without changes of regression. 